\title{
Lormetazepam addiction: data analysis from an Italian medical unit for addiction
}

This article was published in the following Dove Press journal:

Risk Management and Healthcare Policy

II June 2012

Number of times this article has been viewed

\section{Marco Faccini' \\ Roberto Leone ${ }^{2}$ \\ Benedetta Pajusco' \\ Gianluca Quaglio' \\ Rebecca Casari' \\ Anna Albiero' \\ Monia Donati ${ }^{2}$ \\ Fabio Lugoboni'}

'Department of Internal Medicine, Addiction Unit, ${ }^{2}$ Pharmacology Unit, Reference Center for Education and Communication within the World Health Organization Program for International Drug Monitoring, University Hospital of Verona, Verona, Italy
Correspondence: Roberto Leone Pharmacology Unit, Reference Centre for Education and Communication within the World Health Organization Programme for International Drug Monitoring, University Hospital of Verona, P le LA Scuro I0, 37I34,

Verona, Italy

Tel +390456027602

Fax +390458124876

Email roberto.leone@univr.it
Background: The purpose of this study was to determine, in the context of a hospital addiction unit, which benzodiazepines were abused and to look for correlations with the characteristics of detoxified patients.

Methods: A retrospective study was carried out using the database of hospital admissions to the addiction unit for detoxification from 2003 to 2010.

Results: Of 879 admissions to the addiction unit during the seven-year period, 281 were for benzodiazepines. The percentage of patients addicted only to benzodiazepines was higher among females than males. Benzodiazepine consumption had started as a drug addiction behavior in only $10 \%$ of cases. The main sources of prescription identified were general practitioners ( $52 \%$ of cases) or compliant pharmacists (25\%). Overall, 15 different benzodiazepines were abused, with lormetazepam being the most commonly used (by 123 patients, $43.8 \%$ of the total).

Conclusion: Our data show that, outside the population of multidrug addicts, there is an underestimated group of chronic benzodiazepine consumers who are often not referred to medical institutions for treatment. Even in the group of patients addicted to one substance only, we observed an abnormal number of requests for detoxification from lormetazepam, which appears to be more "popular" than other benzodiazepines. This drug should be prescribed according to stricter criteria and submitted to closer control.

Keywords: lormetazepam, benzodiazepines, addiction, inpatient detoxification

\section{Introduction}

Benzodiazepines are being prescribed more and more in almost all Western countries. The World Health Organization, since 1988, has labeled them "essential drugs" that should be available in all countries for medical purposes. ${ }^{1}$ Despite their relative safety, issues remain relating to the potential abuse, withdrawal, and side effects of benzodiazepines. There is a wide gap between the recommendations for rational use and actual medical practice. Several epidemiological studies have shown quite a high prevalence of their use in the general population, with variations from one country to another and from one study to another. ${ }^{2-8}$

The US federal government has tracked the rates of self-reported, nonmedical (eg, nontherapeutic) use of a variety of drugs within the US for more than three decades. Nonmedical use is far less common than medical use of benzodiazepines, but is nonetheless part of the problem of nonmedical use of prescribed controlled substances.

A series of US national surveys tracking medical use of benzodiazepines showed that use peaked in 1976 and declined by about $25 \%$ in the late $1980 \mathrm{~s}^{9}{ }^{9}$ 
A community-based study of a population of older US adults ( $\geq 65$ years) followed from 1987 to 2002 found that $5.5 \%$ of men and $9.8 \%$ of women were using benzodiazepines at baseline; $50 \%$ of users in the age group 65-74 years continued regular use of benzodiazepines at follow-up in $2002 .^{10}$ It was estimated that $1.6 \%$ of the US population are chronic benzodiazepine users. ${ }^{11}$

Large US population surveys funded by the Agency for Healthcare Research and Quality show that outpatient treatment for anxiety disorders nearly doubled between 1987 and 1999 , but remained extremely low (from $0.43 \%$ to $0.83 \%$ of the general population). ${ }^{12}$ The rate of benzodiazepine prescription declined over that time, while the number of antidepressant prescriptions increased. For many anxious patients, a combination of antidepressant and benzodiazepine medications may be the most effective treatment.

In Italy, the cost of benzodiazepines is not reimbursed by the National Health Service, so data on their use are difficult to gather, and can be inferred only from specific questionnaires and information about sales. Over half of the people who take benzodiazepines ( $9 \%$ of the population, according to data which are not recent) are chronic consumers and, of these, $15 \%-44 \%$ are addicted. ${ }^{13}$

Benzodiazepine consumption is slowly growing and abuse is increasing in Italy. Table 1 gives sales data for the five most commonly consumed benzodiazepines from 1983 to 2010, showing a marked increase between 1983 and 1990. In the following years, overall benzodiazepine consumption became basically stable, with variations concerning single drugs. ${ }^{14}$

Benzodiazepine addiction is a widespread phenomenon, but paradoxically is of little interest to scientific research. Medical literature does not suggest anything new compared with the classic treatment approach (gradual reduction with long-acting benzodiazepines) and severe abuse is underestimated, even though withdrawal crises are potentially severe and dangerous. The purpose of this study, conducted in the context of a hospital addiction unit, was to determine which benzodiazepines were abused, and to look for correlations with the characteristics of detoxified patients.

Table I Italian benzodiazepine consumption in specific years

\begin{tabular}{lllll}
\hline Drug & $\mathbf{1 9 8 3}$ & $\mathbf{1 9 9 0}$ & $\mathbf{2 0 0 5}$ & $\mathbf{2 0 1 0}$ \\
\hline Lorazepam & 10.6 & 15.4 & 14.2 & 13.3 \\
Lormetazepam & 1.1 & 3.6 & 11.5 & 13.3 \\
Alprazolam & 0.0 & 1.4 & 6.7 & 8.0 \\
Triazolam & 1.1 & 6.8 & 3.1 & 3.4 \\
Delorazepam & 2.9 & 3.9 & 2.7 & 2.6 \\
\hline
\end{tabular}

Note: Data expressed as defined daily doses per 1000 inhabitants per day.

\section{Materials and methods Design}

The present report is a cross-sectional survey. A retrospective study was carried out using the electronic database of hospital admissions to our addiction unit. The data listed below are recorded in this database.

\section{Setting and detoxification procedures}

Our addiction unit has four beds for inpatient detoxification from various substances (benzodiazepines, opioids, alcohol, cocaine, nicotine). Every year we admit about 150 people. For some years, we have treated cases of chronic abuse of high doses of benzodiazepines with a slow-infusion flumazenil protocol, as suggested by Gerra et al. ${ }^{15}$ This approach makes it possible to stop taking extremely high doses of benzodiazepines completely and very quickly (4-7 days); it is well tolerated and has very few side effects. Flumazenil acts as a partial agonist and produces a resetting of benzodiazepine receptors which, by the end of treatment, have virtually gone back to normal. Flumazenil treatment is also suitable for patients who abuse several different drugs, who suffer from a borderline personality disorder, or who have other psychiatric conditions; in these cases, patients with well structured post-hospitalization therapeutic programs are given preference.

Patients are selected by a staff doctor in the course of a single consultation dedicated principally to evaluate the severity of benzodiazepine dependence. Preference is generally given to cases of more serious dependence (higher doses, for a longer period, with more severe withdrawal symptoms during attempts to cut down or stop taking benzodiazepines). The presence of coaddictions, of episodes of major depression (including suicide attempts) or personality disorders are not considered exclusion criteria, but in these cases we require a clinical report and the consent of the institutions treating the patients, which are usually psychiatric outpatient services or addiction clinics. Patients with less serious dependence (daily intake lower than five times the defined daily dose) are normally sent back to the doctors in charge of their case with instructions for slow tapering of their dose in an outpatient setting.

At the moment, treatment also includes preventive preparation using antiepileptic drugs to prevent the risk of convulsions. ${ }^{16}$ In addition, during the first few days, clonazepam is given at progressively lower doses. Even in cases of particularly high doses of benzodiazepines, more than 12 days of hospitalization are rarely necessary. ${ }^{17-19}$ 


\section{Data collection}

Patient demographics, duration, administration route, and mean daily dose of the benzodiazepine used in the preceding 3 months, reason for benzodiazepine prescription, other coabuse or detoxification substances, and concomitant psychiatric disorders were noted when subjects were admitted into our addiction unit. To compare the dose of different benzodiazepines, we used the defined daily dose. ${ }^{20}$

\section{Statistical analysis}

Categorical variables were compared using bivariate analysis with the Chi-square test or with Fisher's Exact test. Statistical analyses were conducted using SPSS 11.5 statistical software (SPSS version 11.5, SPSS Inc, Chicago, IL).

\section{Results}

Of the total 879 admissions to our addiction unit for detoxification from substances between 2003 and 2010, 281 (32.0\%) were for benzodiazepines. The subjects requiring detoxification came from various Italian regions, $46.3 \%$ from outside the Veneto region. Most subjects $(241,85.8 \%)$ came from regions in northern Italy, followed by those from southern regions $(30,10.7 \%)$ and from central Italy $(10,3.5 \%)$. Table 2 shows the main characteristics of these cases, which were divided into three subgroups, ie, only benzodiazepine addiction, benzodiazepines plus alcohol addiction, and multidrug addiction. The percentage of patients addicted only to benzodiazepines was higher among females $(63.5 \%)$ than males $(31.0 \%)$, while multidrug dependence was more frequent (about 50\%) in males.

The majority of patients were dependent on a single benzodiazepine, $24.9 \%$ of the cases involved abuse of two benzodiazepines, $8.9 \%$ three or more benzodiazepines, with no difference between these three subgroups in terms of patient characteristics.

At least 236 subjects (84.0\%) reported taking benzodiazepines orally. Intravenous administration was found in at least

Table 2 Main characteristics of benzodiazepine abusers

\begin{tabular}{llll}
\hline & Males & Females & Total \\
\hline Number (\%) & $155(55.2)$ & $126(44.8)$ & $28 \mathrm{I}(\mathrm{I00})$ \\
Mean age (years) \pm SD & $41.8 \pm \mathrm{II} .2$ & $44.3 \pm 9.6$ & $42.9 \pm 10.6$ \\
$\begin{array}{l}\text { Age range (years) } \\
\text { Type of addiction }\end{array}$ & $25-79$ & $17-68$ & $17-79$ \\
$\quad$ Only BDZs & & & \\
BDZs + alcohol & $48(3 \mathrm{I} .0)$ & $80(63.5)$ & $128(45.6)$ \\
BDZs + illicit drugs & \\
\hline
\end{tabular}

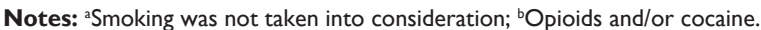
Abbreviations: BZDs, benzodiazepines; SD, standard deviation.
17 subjects (6.7\%), all of whom were multidrug addicts and abusers of lormetazepam in its drop form.

Benzodiazepine ingestion had started as a drug addiction behavior in only $10 \%$ of these cases. In the others, addiction can be classified as iatrogenic, since it was the result of a medical prescription for anxiety problems and/or insomnia, over which the physician subsequently lost control. A psychiatric diagnosis was present in $85.8 \%$ of cases, and the diagnosis was anxiety/depression in $56.6 \%$ of cases. The main sources of prescription identified were general practitioners (52\% of cases) or complaisant pharmacists (25\%). Overall, 15 different benzodiazepines were abused: lormetazepam was the most commonly used (123 patients, $43.8 \%$ of the total), followed by lorazepam (22.4\%), alprazolam (9.6\%), and zolpidem (5.3\%). Surprisingly, the very common benzodiazepine, diazepam, was not frequently involved ( $5 \%$ of our cases).

Table 3 compares lormetazepam and lorazepam, the two benzodiazepines most commonly abused by our patients $(66.2 \%)$. As shown, the variables that we found to be significantly different were average defined daily dose, abuse duration, administration route, and concomitant psychiatric disorders. Another significantly different variable was the pharmaceutical formulation: the liquid formulation (drops) was preferred by 122 of $123(99.2 \%)$ abusers of lormetazepam, whereas 62 of 63 (98.6\%) of those who abused lorazepam preferred tablets. The other variables analyzed, which proved not to be statistically significant, were gender, age, year of hospitalization, schooling, occupational status, multidrug addiction, and geographical origin (northern, central, or southern Italy).

\section{Discussion}

Even though it is common practice in Italian addiction clinics to reduce the prescription of benzodiazepines to a minimum, it has proved impossible to wipe out improper consumption. In the past, the benzodiazepine most commonly used in cases of addiction was flunitrazepam, but in more recent years a tendency towards abuse of lormetazepam has frequently been observed in clinical practice, although not documented in the literature. Those who have experience in dealing with illegal addiction will not be surprised to learn that today the benzodiazepine most sought after by multidrug addicts is lormetazepam, which therefore has its own illegal market. Lormetazepam, a short-acting to intermediateacting 3-hydroxybenzodiazepine derivative, is available in many industrialized countries as a generic drug, or else under many trade or brand names as $1 \mathrm{mg}$ and $2 \mathrm{mg}$ tablets. 
Table 3 Bivariate analysis of lormetazepam (no 123) and lorazepam (no 63) abusers

\begin{tabular}{|c|c|c|c|}
\hline $\begin{array}{l}\text { Significant } \\
\text { variables }\end{array}$ & Lormetazepam & Lorazepam & $P$ value \\
\hline $\begin{array}{l}\text { Average defined } \\
\text { daily dose } \\
\text { (Cl 95\%) }\end{array}$ & $\begin{array}{l}74.3 \\
(56.1-92.4)\end{array}$ & $\begin{array}{l}19.3 \\
(6.6-32.0)\end{array}$ & $<0.00 \mathrm{I}^{\mathrm{a}}$ \\
\hline $\begin{array}{l}\text { Average months } \\
\text { of abuse } \\
(\mathrm{Cl} 95 \%)\end{array}$ & $\begin{array}{l}87.4 \\
(71.6-103.2)\end{array}$ & $\begin{array}{l}135.4 \\
(101.5-169.3)\end{array}$ & $0.004^{\mathrm{a}}$ \\
\hline \multicolumn{4}{|c|}{ Route of assumption (no) } \\
\hline $\begin{array}{l}\text { Oral } \\
\text { Other }\end{array}$ & $\begin{array}{l}95(77 \%) \\
28(23 \%)\end{array}$ & $\begin{array}{l}56(89 \%) \\
7(11 \%)\end{array}$ & $0.039^{b}$ \\
\hline \multicolumn{4}{|l|}{ Formulation (no) } \\
\hline $\begin{array}{l}\text { Oral solution } \\
\text { Capsules }\end{array}$ & $\begin{array}{l}\text { I } 22(99.2 \%) \\
\text { I }(0.8 \%)\end{array}$ & $\begin{array}{l}\text { I (I.4\%) } \\
62(98.6 \%)\end{array}$ & $<0.00 I^{\mathrm{b}}$ \\
\hline \multicolumn{4}{|c|}{ Concomitant psychiatric disorders $(\mathrm{no})^{c}$} \\
\hline $\begin{array}{l}\text { Yes } \\
\text { No }\end{array}$ & $\begin{array}{l}20(16 \%) \\
102(84 \%)\end{array}$ & $\begin{array}{l}3(5 \%) \\
59(95 \%)\end{array}$ & $0.018^{b}$ \\
\hline
\end{tabular}

Notes: ${ }^{\text {aANOVA test; }}{ }^{\text {b}}$ Fisher's exact test; ${ }^{\mathrm{C}}$ This information was unavailable for two subjects.

Like many other benzodiazepines, it has hypnotic, anxiolytic, anticonvulsant, sedative, and skeletal muscle relaxant properties. ${ }^{21}$ Lormetazepam is not approved for sale in the US or Canada, despite the fact that a license to market the drug has been requested more than once (eg, in 1981, 1982, and 1983 in the US). Unfortunately, it was not possible to obtain information about the reasons why these applications were rejected.

To our knowledge, evidence has never been reported in the scientific literature of greater addictive properties of lormetazepam compared with other benzodiazepines, nor have there been studies of abuse of megadoses of lormetazepam. The total lack of data in the literature about abuse of lormetazepam may be due to the fact that the alcohol solution formulation is marketed only in Italy and Spain.

It is noteworthy that among abuse-provoking drugs, flunitrazepam is completely absent from our series. This is surprising in the light of a recent study involving thousands of benzodiazepine users which found that flunitrazepam was the substance with the highest abuse potential. ${ }^{22}$

However, our data show that, outside the population of multidrug addicts, there is an underestimated group of chronic benzodiazepine consumers who are often not referred to medical institutions for treatment. These cases are often due to medical prescriptions that have got out of control, causing real iatrogenic overdosing. The subjects are iatrogenic abusers who suffer from severe personal problems and have no immediate therapeutic way out. Very often they are people with significant psychiatric disorders in whom drug addiction is not considered the main problem at the time. ${ }^{23,24}$ However, when our addiction unit started a new approach to benzodiazepine detoxifications, we received requests from "normal" subjects addicted to one substance only, incapable of stopping the tranquilizer or hypnotic drug they had been prescribed at a difficult time in their lives and who had gradually increased the dose above the upper therapeutic limit.

The finding that surprised us was that even in the group of patients addicted to one substance, we observed an abnormal number of requests for detoxification from lormetazepam which could not be completely accounted for by information concerning the Italian market. The properties of this drug, which is available as a generic but is much more widely appreciated in its original patent form, appear to be unusual compared with those of other benzodiazepines. Some features seem to make abuse easier, ie, its high therapeutic index and its formulation in drops. Another relevant factor is the presence of $95 \%$ alcohol in the drop formulation, ie, $20 \mathrm{~mL}$ of alcohol per bottle. This factor may be negligible at therapeutic doses, but may play an important role when abuse leads to substantial doses.

Comparisons between lormetazepam solution and tablets were made in two different studies in healthy volunteers and in patients suffering from insomnia. In both studies, the solution showed a faster and higher deposition rate than the tablet formulation. ${ }^{25,26}$

In our patient series, lormetazepam and lorazepam were the two benzodiazepines most commonly involved, accounting for about $66 \%$ of cases. However, while these two drugs were consumed in approximately equal proportions by the general population (see Table 1, 2005 and 2010), in our patients the number of abusers of lormetazepam was approximately double that of lorazepam. The two drugs are available in Italy both as tablets and as drops, but whereas in our series lorazepam abuse concerns mainly tablets, lormetazepam abuse concerns almost exclusively the drop formulation. The sales trend of lormetazepam is justified by its greater effectiveness/power compared with other benzodiazepines, but this certainly also conceals an excessive consumption by a subgroup of chronic addicts.

The differences found in our analysis between lorazepam and lormetazepam users suggest a greater addictive power of lormetazepam in its liquid formulation. In our opinion, these differences are amplified by the presence of nonnegligible quantities of alcohol in the lormetazepam solution (each bottle contains $20 \mathrm{~mL}$ of ethyl alcohol at 95\%), which also has a more pleasant flavor than the lorazepam 
formulation. We also think that the discrepancy between these findings, which all point to a clearly greater addictiveness of lormetazepam, and the total lack of such evidence in the literature, is due to the fact that the liquid formulation is not sold on the international market. It is not impossible that the tablet formulation strongly reduces the addictive potential of lormetazepam to the level of other benzodiazepines with an intermediate-short half life. Should this finding be confirmed by specific studies, it might call into question the maintenance of this formulation on the market, or discourage its introduction where it is not available, as happened in many countries after alarm spread about the abuse of flunitrazepam ${ }^{27}$ and, to a lesser extent, of temazepam. ${ }^{28}$

The lack of detoxification from flunitrazepam in our addiction unit can be explained by several factors. Flunitrazepam was widely abused by drug users throughout the 1980s and 1990s. To limit this phenomenon, specific regulatory barriers were put in place, ie, drops were withdrawn from circulation to avoid injection misuse, while tablets were available only at the dosage of $1 \mathrm{mg}$ and the contents of the packet were reduced by half. More recently, in Italy, there have been new specific restrictions regarding prescription of flunitrazepam. These regulatory barriers seem to be effective in limiting inappropriate use of the drug, as confirmed by Italian consumption data.

In conclusion, in addition to pointing out the increase in the number of requests for detoxification from severe benzodiazepine abuse, we wish to emphasize the greater dangers of some of these drugs and the possible role played by the type of pharmaceutical formulation available on the market. In particular, the liquid formulation of lormetazepam, which appears to be more "popular" than other benzodiazepines, should be prescribed according to stricter criteria and submitted to closer controls, because these limitations have been effective in drastically limiting the abuse of flunitrazepam.

\section{Disclosure}

None of the authors have a conflict of interest to disclose and this study was conducted without any funding sources.

\section{References}

1. World Health Organization. The use of essential drugs: third report of the World Health Organization Expert Committee. Geneva, Switzerland: World Health Organization; 1988. Available from: http://www. whqlibdoc.who.int/trs/WHO_TRS_770.pdf. Accessed May 18, 2012.

2. Marriott S, Tyrer P. Benzodiazepine dependence. Avoidance and withdrawal. Drug Saf. 1993;9(2):93-103.

3. Chouinard G. Issues in the clinical use of benzodiazepines: potency, withdrawal, and rebound. J Clin Psychiatry. 2004;65 Suppl 5:7-12.
4. Ashton H. The diagnosis and management of benzodiazepine dependence. Curr Opin Psychiatry. 2005;18(3):249-255.

5. Lagnaoui R, Depont F, Fourrier A, et al. Patterns and correlates of benzodiazepine use in the French general population. Eur J Clin Pharmacol. 2004;60(7):523-529.

6. Gorgels WJ, Oude Voshaar RC, Mol AJ, et al. Discontinuation of long-term benzodiazepine use by sending a letter to users in family practice: a prospective controlled intervention study. Drug Alcohol Depend. 2005;78(1):49-56.

7. Fang SY, Chen CY, Chang IS, Wu EC, Chang CM, Lin KM. Predictors of the incidence and discontinuation of long-term use of benzodiazepines: a population-based study. Drug Alcohol Depend. 2009;104(1-2):140-146.

8. Petitjean S, Ladewig D, Meier CR, Amrein R, Wiesbeck GA. Benzodiazepine prescribing to the Swiss adult population: results from a national survey of community pharmacies. Int Clin Psychopharmacol. 2007;22(5):292-298.

9. Dumont RL. Abuse of benzodiazepines: the problems and the solutions. A report of a Committee of the Institute for Behavior and Health, Inc. Am J Drug Alcohol Abuse. 1988;14 Suppl 1:1-69.

10. Stowell KR, Chang CC, Bilt J, Stoehr GP, Ganguli M. Sustained benzodiazepine use in a community sample of older adults. $J$ Am Geriatr Soc. 2008;56(12):2285-2291.

11. Mellinger GD, Balter MB. Prevalence and patterns of use of psychotherapeutic drugs: Results from a 1979 national survey of American adults. In: Tognoni G, Bellantuono C, Lader M, editors. Epidemiological Impact of Psychotropic Drugs. Amsterdam, The Netherlands: Elsevier; 1981.

12. Olfson M, Marcus SC, Wan GJ, Geissler EC. National trends in the outpatient treatment of anxiety disorders. $J$ Clin Psychiatry. 2004;65(9):1166-1173.

13. Magrini N, Vaccheri A, Parma E, et al. Use of benzodiazepines in the Italian general population. Prevalence, patterns of use and risk factors for use. Eur J Clin Pharmacol. 1996;50(1-2):19-25.

14. Italian Medicine Agency. The use of drugs in Italy. National report 2010. Available from: http://www.agenziafarmaco.gov.it/sites/default/ files/rapporto_osmed_2010_0.pdf. Accessed May 28, 2012. Italian.

15. Gerra G, Zaimovic A, Giusti F, Moi G, Brewer C. Intravenous flumazenil versus oxazepam tapering in the treatment of benzodiazepine withdrawal: a randomized, placebo-controlled study. Addict Biol. 2002;7(4):385-395.

16. Lugoboni F, Faccini M, Quaglio GL, Albiero A, Casari R, Pajusco B. Intravenous flumazenil infusion to treat benzodiazepine dependence should be performed in the inpatient clinical setting for high risk of seizure. J Psychopharmacol. 2011;25(6):848-849.

17. Quaglio GL, Lugoboni F, Fornasiero A, Lechi A, Gerra G, Mezzelani P. Dependence on zolpidem: two case reports of detoxification with flumazenil infusion. Int Clin Psychopharmacol. 2005;20(5): 285-287.

18. Hood S, O'Neil G, Hulse G. The role of flumazenil in the treatment of benzodiazepine dependence: physiological and psychological profiles. J Psychopharmacol. 2009;23(4):401-409.

19. Lugoboni F, Faccini M, Quaglio G, Casari R, Albiero A, Pajusco B. Agonist substitution for high-dose benzodiazepine-dependent patients: let us not forget the importance of flumazenil. Addiction. 2011;106(4):853.

20. Guidelines for ATC classification and DDD. 5th ed. Oslo, Norway: WHO Collaborating Center for Drug Statistics Methodology; 2002.

21. Luscombe DK. Lormetazepam - plasma concentrations in volunteers following sublingual and oral dosing. Psychopharmacology Suppl. 1984;1:99-104.

22. Pradel V, Delga C, Rouby F, Micallef J, Lapeyre-Mestre M. Assessment of abuse potential of benzodiazepines from a prescription database using "doctor shopping" as an indicator. CNS Drugs. 2010;24(7):611-620.

23. O'Brien CP. Benzodiazepine use, abuse, and dependence. J Clin Psychiatry. 2005;66 Suppl 2:28-33.

24. Neutel CI. The epidemiology of long-term benzodiazepine use. Int Rev Psychiatry. 2005;17(3):189-197. 
25. Guerra P, Soto A, Carcas AJ, Sancho A, Cassinello A, Frías-Iniesta J. Comparison of lormetazepam solution and capsules in healthy volunteers: early exposure and drug pharmacokinetics. Clin Drug Investig. 2002;22(12):859-866.

26. Ancolio C, Tardieu S, Soubrouillard C, et al. A randomized clinical trial comparing doses and efficacy of lormetazepam tablets or oral solution for insomnia in a general practice setting. Hum Psychopharmacol. 2004;19(2):129-134.
27. Bramness JG, Skurtveit S, Furu K, Engeland A, Sakshaug S, Ronning M. Changes in sale and use of flunitrazepam in Norway after 1999. Tidsskr Nor Laegeforen. 2006;126(5):589-590. Norwegian.

28. Breen CL, Degenhardt LJ, Bruno RB, Roxburgh AD, Jenkinson R. The effects of restricting publicly subsidised temazepam capsules on benzodiazepine use among injecting drug users in Australia. Med J Aust. 2004;181(6):300-304.

\section{Publish your work in this journal}

Risk Management and Healthcare Policy is an international, peerreviewed, open access journal focusing on all aspects of public health, policy, and preventative measures to promote good health and improve morbidity and mortality in the population. The journal welcomes submitted papers covering original research, basic science, clinical \& epidemio- logical studies, reviews and evaluations, guidelines, expert opinion and commentary, case reports and extended reports. The manuscript management system is completely online and includes a very quick and fair peerreview system, which is all easy to use. Visit http://www.dovepress.com/ testimonials.php to read real quotes from published authors.

Submit your manuscript here: http://www.dovepress.com/risk-management-and-healthcare-policy-journal 